\title{
Atlantis
}

Critical Studies in Gender, Culture \& Social Justice

Études critiques sur le genre, la culture, et la justice

\section{"It feels a bit like drowning": Expectations and Experiences of Motherhood during COVID-19}

\section{May Friedman, Kori Kostka Lichtfuss, Lucas Martignetti et Jacqui Gingras}

Volume 42, numéro 1, 2021

"Covid and the Academy" \& Open-themed Research

URI : https://id.erudit.org/iderudit/1082015ar

DOI : https://doi.org/10.7202/1082015ar

Aller au sommaire du numéro

Éditeur(s)

Mount Saint Vincent University

ISSN

1715-0698 (numérique)

Découvrir la revue

Citer cet article

Friedman, M., Kostka Lichtfuss, K., Martignetti, L. \& Gingras, J. (2021). "It feels a bit like drowning”: Expectations and Experiences of Motherhood during COVID-19. Atlantis, 42(1), 47-57. https://doi.org/10.7202/1082015ar
Résumé de l'article

What is the result of bringing unrealistic and overwhelming conditions of motherhood into the context of a global pandemic? This article aims to explore the impacts of maternal expectations and experiences in the context of COVID-19. Through first-person accounts of eighty self-identified mothers parenting through COVID, we aim to explore "good" mother myths, feelings of failure, and the paradoxical freedoms that occur under pandemic time. (c) May Friedman, Kori Kostka Lichtfuss, Lucas Martignetti, Jacqui Gingras, 2021

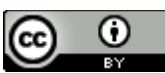

Ce document est protégé par la loi sur le droit d'auteur. L'utilisation des services d'Érudit (y compris la reproduction) est assujettie à sa politique d'utilisation que vous pouvez consulter en ligne.

https://apropos.erudit.org/fr/usagers/politique-dutilisation/ 


\title{
"It feels a bit like drowning": Expectations and Experiences of Motherhood during COVID-19
}

\author{
by May Friedman, Kori Kostka Lichtfuss, Lucas Martignetti, Jacqui Gingras
}

\begin{abstract}
What is the result of bringing unrealistic and overwhelming conditions of motherhood into the context of a global pandemic? This article aims to explore the impacts of maternal expectations and experiences in the context of COVID-19. Through first-person accounts of eighty self-identified mothers parenting through COVID, we aim to explore "good" mother myths, feelings of failure, and the paradoxical freedoms that occur under pandemic time.
\end{abstract}

Keywords: COVID; gender roles; matricentric feminism; motherhood; pandemic
May Friedman is a faculty member in the Ryerson School of Social Work and in the Ryerson/York graduate program in Communication and Culture. Most recently, much of May's research has focused on intersectional approaches to fat studies considering the multiple and fluid experiences of both fat oppression and fat activism. The bulk of May's work focuses on unstable identities, including bodies that do not conform to traditional racial and national or aesthetic lines.

Kori Kostka Lichtfuss is a Registered Dietitian and is currently completing her MHSc at Ontario Tech University in the Community, Population and Public Health Program.

Lucas Martignetti is a Master of Health Sciences student in Ontario Tech University's Community, Public and Population Health Program. His research focuses on health equity, and his thesis examines barriers and facilitators to equitable access to naloxone in Durham Region, Ontario, Canada.

Jacqui Gingras is an Associate Professor in the Department of Sociology at Ryerson University in Toronto. Her research explores social health movements, fat studies, radical democratic pedagogies, and decolonization of health professions within the entanglements of colonial neoliberal economics and intersectional feminisms. She has published in the Fat Studies Journal, Journal of Sociology, and Critical Public Health. She is the founding editor of the Journal of Critical Dietetics, an open-access, peer-reviewed journal at http://criticaldietetics.ryerson.ca. 


\section{Introduction}

Motherhood is not for the faint of heart. At the best of times, in privileged circumstances, motherhood can be depleting, overwhelming, and extreme, thieving identity and time. The total immersion of motherhood may be exponentially more demanding at the intersections of identities-for single mothers, mothers who experience racism, homophobia, transphobia, or oppression based on disability or madness (O'Reilly 2007). ${ }^{1}$ Much of the overwhelming impact of motherhood is rooted in the extent to which maternal parenting is established according to a set of scripts setting out specific behaviours which draw upon key expectations that govern the maintenance and expression of a challenging relationality between mother and child (Ennis 2014; O'Reilly 2004). While the specifics vary across social contexts, maternal expectations, as a byproduct of colonialism, have festered into many Western and colonized spaces including Canada. Motherhood is accompanied by conditions that guarantee failure and that negate attempts to "succeed."Indeed, success is elusive and undefined, ensuring that hegemonic motherhood entails endless self-governance and punishing guilt and shame (Hays 1998; Warner 2005). What is the result of bringing unrealistic and overwhelming conditions of motherhood into the context of a global pandemic? This article aims to explore the impacts of maternal expectations and experiences in the context of COVID-19 through first-person accounts of eighty self-identified mothers. We aim to explore good mother myths, feelings of failure, and the paradoxical freedoms that occur under pandemic time.

\section{Setting the Stage: COVID, Mothers, \& Mothering}

Limited data is emerging which explores the impacts of COVID (especially lockdowns of schools, and other childcare settings) on parents and caregivers (O'Reilly and Green 2021; Sodha 2020; Cohen and Hsu 2020). We aim here to bring the specific experiences of pandemic parenting into dialogue with the preexisting expectations of parents, and in particular, of mothers (O'Reilly 2020). We use the term "mother" deliberately, aiming to avoid degendering the often very gendered landscape of caregiving labour; at the same time, we aim to understand "mother" as a porous term encompassing anyone who chooses to describe themselves in this way.

This study and our findings are rooted in the robust lit- erature of motherhood studies (O'Reilly 2007; Takseva 2018), and matricentric feminism (O'Reilly 2019) that consider the ways the institution of patriarchal motherhood-the expectations and expertise which crowd around maternal labour-may limit maternal "agency, authority, autonomy and authenticity” (O'Reilly, 2004, 15). Literature around maternal expectations and good mother myths (Nathanson and Tuley, 2009) suggests that mothers, in particular, are blamed for myriad social ills (Caplan 1989; Ladd-Taylor 2004) and, furthermore, that mothers internalize this blame and seek to control the maternal environment to avoid social sanction (Hays 1998). This pressure, while widely critiqued, has not abated in contemporary contexts, suggesting that we should ask, "[I]n a world which values independence, why are we still engaging in 'intensive mothering,' why does it prevail, and what other models are additional possibilities or alternatives?" (Ennis 2014, 3).

It is difficult to consider the impacts of motherhood on women's autonomy without exploring other ideological underpinnings. This article thus contextualizes contemporary motherhood by borrowing from analyses of neoliberalism and feminist political economy. While an exhaustive engagement with this literature is beyond the scope of this article, we consider the ways that "Mothers are the primary producers, consumers and reproducers of the neoliberal world" (Vandenbeld Giles 2014, 1). In the limited scholarly and popular materials which explore the impacts of COVID-19 on mothers, the economic ramifications of caregiving labour and the tensions between mothers as carers and paid workers are overwhelmingly discussed, suggesting, as feminist economist Silvia Federici states in the New York Times Magazine, " $[\mathrm{T}]$ he morass of America's social ills might be traceable to an incorrect relationship to work and the question of whose work is valuable" (Kisner 2021, para. 7). Andrea O'Reilly and Fiona Joy Green, in their timely and comprehensive collection on mothers and COVID-19, put it succinctly: "Despite the cataclysmic upheavals of the pandemic, one fact remains unchanged: Motherwork remains invisible, devalued, and taken for granted" (2021, 22). Our exploration of mothers' experiences is thus grounded by matricentric feminist analyses informed by discussion of the gendered dimensions of public and private labour.

We open by describing the conditions of our study which was undertaken over three and a half months in summer 2020. We consider the demographic limitations of our sample, as well as the methods we used for ana- 
lysis. Following a discussion of methods, we explore key themes, including the expectations of participants for good motherhood, feelings of failure engendered by pandemic parenting, and the interesting ways that COVID has, in some cases, allowed for a shift or reduction in maternal expectations. We root these themes in the literature and scholarship of motherhood studies.

\section{Methods}

Our study was conceived as COVID lockdown conditions began in spring 2020 and was funded through a small COVID Rapid Response grant through Ryerson University. We responded to our own experiences as well as calls such as the following, published at the onset of the pandemic:

We are not aware of any gender analysis of the outbreak by global health institutions or governments in affected countries or in preparedness phases.... We call on governments and global health institutions to consider the sex and gender effects of the COVID-19 outbreak, both direct and indirect, and conduct an analysis of the gendered impacts of the multiple outbreaks, incorporating the voices of women on the front lines of the response to COVID-19 and of those most affected by the disease. (Wenham, Smith and Morgan 2020, 846, emphasis ours)

Because we wanted to prioritize individual narratives and acknowledge some of the tumultuous experiences we were hearing about (and living through), we created an anonymous online survey with open-ended questions that allowed for fairly substantial long-form written responses. This survey was shared through social media including a range of mothering Facebook groups. While some of these groups were more generalized geographically, some had a specific focus on Toronto and southern Ontario. Recruitment began on June 13, 2020 and ran until the end of September 2020 (a period which was characterized by lockdown and school/childcare closures in most of Canada, as well as in many other jurisdictions), generating a total of eighty responses. While the survey did not explicitly capture information about the physical location of respondents, an examination of responses suggests that the majority were from people residing in Canada, with an overrepresentation of Ontario, Quebec, and British Columbia residents.
The overall range of respondents showed a relatively high degree of diversity around some axes and was more homogenous in other regards, particularly in regards to race and class, with a sample that skewed heavily toward white and middle-class participants. Importantly, the survey deliberately avoided any type of identity rubric, instead inviting respondents to identify any aspects of their social location or lived experiences that felt relevant. Mindful of the intersectional nature of identities, we decided that providing a checklist for identities, such as race and class, felt reductionist and instead invited participants to reflect on their own multiple and complex identities in their own words. As a result, we cannot describe the overall demographic makeup of the group with precision, but we can draw some broad strokes about the grouping.

The eighty respondents ranged in age from 26 to 62 years old and while not all surveys revealed the ages of children, those that did showed parenting of children from newborn to age 26. As mentioned above, the sample overrepresented white-identifying participants, with approximately 85 percent of respondents selfidentifying as white. Among those responses which explored family configuration, more than 80 percent were in male-female partnerships, although approximately a third of the respondents in partnerships with men selfidentified as queer, bisexual, pansexual, and otherwise not straight. Approximately 7 percent of respondents were single mothers and others lived in blended families, or multigenerational households. The sample skewed toward the middle class, with the vast majority of respondents, over 90 percent, identifying as middle class or higher. Respondents were mostly employed in paid labour with approximately 85 percent suggesting that their work had moved to the home as a result of COVID, in stark contrast to only about half of male partners having moved toward home employment. Meaningfully, almost a quarter of the sample reported lost work or lost hours due to COVID, with male partners of respondents significantly less impacted by reduced employment.

This sample does not adequately address the range of possible maternal experiences of living through COVID; the sample is relatively homogenous and more problematically, insufficiently representative of racial and ethnic diversity, highlighting experiences of white middle-class families with one female-identified and one male-identified parent. The responses of this survey do not address the much greater impact of COVID among communities of colour (Golestaneh et al 2020) or the heightened 
impacts for people and families living in poverty. We wondered if, despite robust recruitment efforts in a range of contexts, including targeted outreach to online groups for mothers of colour and queer mothers, underrepresented mothers might have been so besieged by the initial impact of lockdown that a survey like this might have seemed overwhelming. Furthermore, our online survey required a threshold level of entry: access to the Internet, sufficient bandwidth to run the survey, and sufficient functionality in English-this also excluded some potential respondents. There is no question that further research is required in order to broaden this sample and understand the impacts for mothers who live in a range of intersections. That said, the themes which emerged from this dataset nonetheless show some important trends in the ways that expectations of motherhood are used to judge mothers and furthermore are internalized by mothers.

The research team spent fall 2020 reading and re-reading responses and undertaking a collective thematic analysis (Braun \& Clarke 2006). Key themes emerged around the ways that mothers were experiencing upheaval due to the changed balance in caregiving and paid employment roles, confirming that "gender disparities in households with children have been amplified as a result of the pandemic" (Johnston, Mohammed and van der Linden $2021,1132)$. In addition, perhaps in reaction to a question asked about what the performance of a good mother would look like during COVID, many respondents considered the ways that expectations of intensive motherhood were playing into their experiences as well as their internal expectations of themselves. We explore some of the themes which emerged from the survey responses around good motherhood, feelings of failure, as well as unusual or paradoxical shifts in stressors experienced in the time of COVID. The quotes offered below were emblematic of broader themes that emerged from the research; they were included as exemplars of themes and ideas which were evident across a range of responses.

\section{Key Themes and Discussion}

\section{"The 'good mother' is not me":. Articulating good motherbood}

In colonial and western cultures, mothers have long been seen as the architects for children's success or failure (Caplan 1989). Mothers are meant to ensure that children are healthy, ambitious, and successful. In other words, mothers are meant to ensure a neverending supply of functional neoliberal capitalist citizens (Vandenbeld Giles 2014; Ennis 2014). When children do not meet these standards, physiologically or temperamentally, mothers receive blame and sanction (Friedman 2015). As Vandenbeld Giles notes, "While it is true that women and mothers form the productive, reproductive and consumptive base to ensure neoliberalization, mothers are still a long way from claiming collective power and material gain for themselves and their children" $(2014,5)$.

In some cases, particularly for Black and Indigenous mothers as well as mothers with disabilities, families are brought under child protection scrutiny. The overrepresentation of Black and Indigenous kids under the surveillance of child welfare agencies reflects multi-pronged racist and colonial attacks (Pon et al. 2017). Black and Indigenous families, as well as other families of colour, face unending racism that limits opportunities for "appropriate" parenting, and are then accused of neglect. This hearkens back to a colonial history in which Indigenous land was pillaged and then starving Indigenous people were maligned for asking for state support (Fortier and Wong 2018). In other words, patriarchal motherhood creates impossible expectations (especially for particular people and identities) and then judges and polices mothers when these expectations cannot be met.

Against this backdrop, participants were asked to discuss how a good mother would behave in the midst of pandemic parenting and to explore their reactions to those expectations. Responses to this question were explosive, with respondents articulating shame, rage, frustration, and grief. Importantly, the majority of responses were unhesitating in providing a clear description of good motherhood, suggesting that the archetype of effective maternity is unsubtle and pernicious. Even when respondents rejected this performance, they were quickly able to describe it, as in this succinct response: "[A] good mother would be doing daily crafts/activities, homemade meals and super clean house. It started off that way, but has slowly decreased as the time has gone on." A composite good mother thus emerged from the range of responses describing a selfless, patient, innovative nurturer who is capable of endless improvisation and is impervious to provocation. Like a unicorn, this beautiful creature is utterly mythical, which some respondents noted:

It seems like we should be homeschooling, not working, making sandwiches shaped like whales, baking bread, and watching 
movies with partners (and we should have partners). It's ok [for] us to make the sacrifices for our kids' health and safety. Ours is not in question or supported. Forget how we make money, we should have husbands out working while we go back to the 1950's and stay home and devote our whole being to our children. It is so much pressure and sending my kids to school feels like it's announcing my 'bad mom' status to the world. I feel guilty. I also feel angry. I want to work and I also have to work.

This response names the archetypal good mother (creative and resource rich) and, while articulating guilt, also notes the economic limitations which make stereotypical good motherhood an impossibility for most people. Notably, however, the majority of responses articulated a good mother ideal and often grieved the inability to reach that ideal in the midst of COVID. One mother noted, "Last year, I considered myself a good mother. I made my son's food, I limited screen time, ensured we got out of the house, engaged in playdates and mothers' groups. None of that applies during the pandemic." While the pandemic altered maternal capacities, it is meaningful to observe that the expectations of good motherhood articulated in these answers seems to require intense effort even outside of COVID times.

Responses reflected the expectation of maternal selflessness. For example, one respondent who was working as a teacher at the same time as caring for young children stated, "I've always struggled with the idea of a 'good' $\mathrm{mom} /$ parent being one that puts the needs of their child above all else. No matter what's going on, the child always comes first. This ideal caused a lot of anxiety for me when I had to choose between spending my time with my children, and spending my time on my students/ work... not to mention on myself, which was basically nonexistent." This mother's view exemplifies many responses in which participants spoke to anxiety and grief about shortchanging children and work, with only cursory acknowledgement of their own needs. The extent to which maternal emotional labour was taken for granted was notable; a few respondents noted that pragmatic and emotional caregiving labour (i.e., planning for and worrying about children) was largely in the maternal domain, especially for women parenting with men. When self-care was articulated as part of the domain of good motherhood, it was still in aid of children's well-being, as in the following response: "A good parent... [is] setting a good example by eating healthy and engaging in meaningful activities with and without the kids. I don't think I'm meeting this ideal at all. I'm frazzled and stressed and worried all the time. I want to chill and play, but I also want to lock myself in the bathroom and be alone. It makes me feel terrible."

Importantly, there was a deep degree of internalization of good mother ideals: respondents were extremely hard on themselves for failing to match idealized expectations. One mother noted, “'Good' moms are in control, positive, have time to listen to their kids and make sure meals are cooked and the [ability to] try to keep the house in order. I feel I am doing none of these things and often disappointed in myself." Another similarly noted, "A good mother is creating structure for their kids, is patient with their feelings about all of this, is engaged with them, making sure they are still connected with friends, nature, etc. I feel I would get a D or E [failing grade] in this if I were being graded. It makes me feel sad, regretful, lost, guilty, VERY anxious, sick to my stomach." Overall, it was evident that participants had no problem describing what constitutes good motherhood, and that this benchmark was often used as a way to measure maternal shortcoming.

\section{"I am not a good mother even though I try so bard to be": Failing maternal expectations}

As Sharon Hays (1998) and Judith Warner (2005) articulate, mothers know what good mothers should be doing and are deeply critical of the places where they fall short. So, what are the expectations of good mothers? Some respondents suggested that mothers need only be "good enough," however, many indicated that they felt themselves falling short of even "good enough." While participants in this study generally indicated that their children's basic needs were met, there was still a great deal of judgment for the places where mothers understood themselves to be inadequate. In other words, participants in general indicated that more than basic care is required for children to thrive. They named a lack of engagement and mental presence as their chief failing, suggesting that in the contemporary moment, good motherhood is predicated on a deep degree of maternal attention (Hays 1998; O'Reilly 2004). Secondarily, the study indicated that good motherhood requires material resources, noting that games, educational toys and crafts, as well as time free from paid employment, were necessary for children's sustenance. Mothers noted the ways that "the backdrop for intensive mothering is consumer- 
ism" (Ennis 2014, 2). This classed and heteronormative view sets all mothers up to fail, even those who parent under privileged conditions, but it is especially pernicious for mothers parenting outside of mainstream or expected frames.

Mothers named the tensions between wanting to maintain a standard of functionality in employment settings and the need to provide adequate childcare. This cognitive discomfort was extraordinarily high in virtually all responses but notably, many respondents internalized this discomfort and positioned dropped standards, both professionally and in the home, as a personal failing. For example, one mother explained, "I think this experience has forced me to realize that I am stretched in an unhealthy way, that maybe doing it all and having a fulfilling career and less debt aren't as important as I've believed, and that I may have to surrender my wish for a partner that will stand beside me in the business and challenges of our life and make ways to support and fulfill my personal needs." Another mother similarly noted, "Being the parent who is mostly in charge of child care (and home schooling) while also trying to work part time has meant that I am pulled in all directions, never feeling like I can excel at anything. I miss having dedicated hours for paid work versus for parenting." Responses indicated predominantly guilt rather than rage, suggesting that participants have successfully internalized expectations of mothers as superheroes who are meant to effortlessly shoulder unimaginable burdens.

In the context of paid employment, COVID-19 has exposed the frayed infrastructure supporting working parents, landing many families in impossible situations (Fraser 2016). Working parents, and others with caregiver requirements such as elder care and support of families with differing abilities or health needs, have been expected to stay afloat with full or part-time work while also taking on full-time care responsibilities. This is a structural and ideological problem: caregiving labour is underestimated and caregivers are expected to shift and morph to ensure that no balls get dropped on personal and societal levels. Practically, however, this approach has engendered a crisis for caregivers who are genuinely being asked to accomplish more than twenty-four hours worth of labour in any given day. For example, one respondent stated, "The impossible math of trying to work full time and manage two young kids was impossible." Another mother wrote, "No matter how we would try to negotiate it, I always felt it was unbalanced." Another respondent alluded to the ways that balance was barely achievable before COVID, stating that she "was already treading [water] furiously but now feel[s] close to drowning." It is notable that multiple respondents used the analogy of drowning to describe their present circumstances, corroborating the following statement: "Women with child care obligations have seen a dramatic and disproportionate increase in invisible labor as a result of the COVID-19 pandemic" (Johnston, Mohammed and van der Linden 2020, 1133).

While mothers without external labour expectations were not juggling the same tensions as those blending caregiving with paid work, the lack of social supports, including additional caregivers and activities outside the home, has increased caregiving expectations while eliminating any respite for mothers. One respondent presently on parental leave noted, "My mental health has declined immensely. I am submersed in my role as fulltime breastfeeding mother, nothing else happens in my life. I barely get a minute alone to shower these days." Some mothers who experienced this tension articulated feelings of guilt for not enjoying intensive time with children more completely. One mother noted, "I find that too much time together leaves me with a short temper, and I feel like I am not parenting the way I would like to be!" Another stated, "As a mother I feel I am less patient and feel myself struggling more daily than previously." While these mothers' responses partially indicate that better supports would allow them to parent in a way more aligned with their own expectations, it is also notable that there is limited acknowledgement that the primary problem is not a personal one but rather, it is dictated by the structures that ignore the demands on a household created by non-stop parenting.

In addition to tensions between employment and caregiving labour, respondents specifically singled out discomfort at having to take over responsibility for children's education. Many respondents felt guilty and uncomfortable at suddenly needing to pivot toward home schooling in addition to other demands. Mothers noted that they were feeling "anxiety around children having to learn from home. Feeling like I'm not doing enough to facilitate their learning." Respondents reported that pedagogical options offered by school boards were quite limited at the same time that mothers reported intense pressure to keep children's educational trajectories moving along, often at a high personal cost. Respondents reported virtually no support or materials although there were high expectations that school-aged children use the time productively, suggesting that "While neoliberalism iden- 
tifies women only as economic actors, the work of mothering must still be performed and is in fact integral to the reproduction of future neoliberal workers" (Vandenbeld Giles 2014, 6).

A notable number of responses named lowered vigilance with regard to screen time as a key maternal failing. Mothers reported an increased reliance on use of digital media in order to try to keep children quiet while undertaking other tasks. In addition, mothers named the need to provide a constant parade of healthy foods (and the avoidance of "junk" foods) as necessary for proper parenting. One mother noted, "I feel so guilty for the amount of time my kids spend on tech. They are in their rooms so much and I want them to be out, but if they are out of their rooms, they interfere with my work. It is really hard and stressful." This comment was echoed by many participants, a large number of whom expressed a lot of anxiety about the implications of screen time on the physical and mental health of young people. For example, one respondent noted, "The kids have been on screens at rates much higher than I'm comfortable with and I feel constant anxiety about the long-term damage of them being isolated and glued to a screen.” The relative ease offered by screen use as a stop gap for limited childcare seemed to contribute to parental guilt; mothers felt strongly that children would be far better served with greater parental engagement. The virulence of reactions to screen time was notable; one participant exemplified many responses in stating, "I read about how other families have become closer and I think, 'I must be doing this wrong.' I am just more stress[ed], anxious, irritable, and burnt out. No, I have not started baking bread. I think if we didn't have technology or smart phones, our lives would be so much better."

While the research on the impacts of screen time on children's development is ambiguous and often contradictory (Cerniglia and Cimino 2020; boyd 2016), it is notable that, as with convenience foods, as mothers gain time through efficiencies in the household, these options are quickly and deeply maligned. In other words, the fact that even relatively young children can keep busy using screens is quickly re-storied as evidence of maternal failing. Mothers who rely on so-called shortcuts, such as screen time and junk food, are harming their childrennot necessarily because of the intrinsic danger in these materials, but rather because they betray the mothers who use them as insufficiently caring and selfless.

\section{"While we hate the virus, we love that we get to spend extra time together": Exploring alternate expectations}

While the overwhelming tenor of maternal responses was around guilt, rage, and being overwhelmed, a paradoxical finding did emerge among a smaller but significant range of responses, sometimes alongside parallel experiences of discomfort. Specifically, mothers reported the ways that the pandemic and lockdown eliminated particular sources of tension in family life. For example, one respondent noted that avoiding heavy expectations to display her new baby was quite freeing, stating, "I did appreciate the quiet after the baby was born and less pressure to have visitors. Our family could take the time to bond with the new baby without others around." Another noted, "Being able to mother/parent from home has made life MUCH less hectic for us and allowed us to spend more family time together." These hidden benefits of COVID were important to note but also need to be considered within the broader context of maternal expectations and the burdensome demands placed on mothers outside of the pandemic.

Mothers discussed the infinite pulls on their time in prepandemic life, citing the expectation of endless programming and extracurricular involvements. The escape from the rush of contemporary parenting was noted by many respondents as a significant benefit to the present time. For example, one mother noted,

I believe the pandemic has had [a] great benefit on my mothering. It has allowed me to focus more on my child instead of being torn in many different directions-one of which is work, but also running around to play dates and programming. I have felt very freed by the lack of outside (although mostly self-imposed) demands on my time. It has allowed me to relax and enjoy the time with my child and play with him when he asks instead of putting him off because we have places to get to and I have to get preparations done.

Other mothers spoke to the idea that COVID has led to an alteration in maternal expectations. For example, one respondent noted, "Increased family time due to not having to shuttle the kids to sports and other activities has been a bonus." Another stated, "I personally have enjoyed not having to meet social demands (e.g., weekends full of play dates, plans, etc.) As much as these activities 
are important for our whole family, it can get quite exhausting, for me, if I am unable to recharge by myself." On the one hand, these responses may be considered as hidden benefits to the pandemic which has interrupted some aspects of the endless trajectory of success and productivity of neoliberal societies. A more critical look reveals some of the very high expectations placed on parents (specifically mothers) to function as endless schedulers, chauffeurs, researchers, and programmers: it is notable that only a global pandemic allows these expectations to be contested without significant guilt. The stranglehold of maternal expectation suggests that mothers cannot opt out of a full social schedule simply because they are exhausted or require time to recharge, but should instead persevere, stopping only in the extreme instance of the entire world shutting down. While responses show pleasant side-effects to the present situation, such as one mother who stated, "I do feel less stressed and have been taking a little more time for myself during the pandemic," they must be critically assessed for the ways they reveal the burden of expectations placed upon mothers in "normal" times.

While maternal expectations played a part in the endless busyness of pre-COVID life, the fundamental tension between paid employment and caregiving labour was exposed in these paradoxical reactions as well. In many respects, the choice to participate in extracurricular and other social activities is extremely class based: for many working-class parents, paid work is endless and parenting time must be stripped to necessities. Some respondents noted this painful paradox and acknowledged the ways that COVID, by eliminating some forms of paid employment, allowed for rare opportunities for families to connect. For example, one mother noted, "In a lot of ways, the pandemic has been very freeing to us and gives me a new perspective on what I would like our lives to look like. However, the CERB has played a big part in feeling that freedom." This respondent reflects on the Canada Emergency Response Benefit which allowed workers who lost employment due to COVID to receive benefits for a period of time. Responses such as these speak to the desire for many families to pare down the congestion of racing between paid and unpaid labour demands. While virtually all families rely on parental income, the feeling of precarity that thieves time from families is especially acute for working-class and solo-income families. While COVID benefits have thus provided a small silver lining for some families, it is notable that here again, only a pandemic allows the conditions for parents to choose to be with their children as they see fit. Furthermore, as pandemic benefits in many jurisdictions including Canada have withered, these rare opportunities have basically been eliminated, leaving workers with limited flexibility resulting in painful choices each time a child is home sick or childcare is otherwise disrupted in this altered new reality.

Displaying a profound resilience, many respondents noted benefits from COVID but often with deep qualifications. For example, one mother noted that pleasure in having her family gathered was mitigated by concern for her kids' development: "Having my adult kids around more is nice but I feel like it's a limitation for them so not 100 percent enjoyment for me." One mother was more stark in her view of the cost-benefit analysis: "I see very little benefit to mothering/parenting because of social distancing. I try to appreciate the increased time with my son, but it has come at a significant cost to my independence and sense of self worth." Ultimately, the majority of responses could only speak to qualified benefits from the present situation, exemplified in this mother's response: "After six months, I do feel much closer with my children and mostly appreciate the changes in our relationship, although I'm very excited to send them back off to school."

While the study did suggest that mothers internalize a great deal of guilt, there was a notable thread of rage throughout responses. Respondents took on a great deal of responsibility for both children and home, but they also articulated the ways that the current situation is evidence of systemic failure. The rage and frustration which emerged in these responses, while showing evidence of anguish, also displays the profound resilience and resistance put forth by mothers who are experiencing overwhelming conditions, as in this example: "There is no 'good' right now. As long as your child is safe and healthy I think this is the only expectation right now." As noted by Sonia Sodha in The Guardian, there is a paradoxical hope which may be wrung from the intensity of the present situation: "That's the thing about this pandemic: it has revealed deep structural inequalities in class, race and gender that we have long swept under the carpet and without concerted and radical action will undoubtedly make them worse. But the very act of exposure provides an opportunity for change if only we had the imagination" (2020, para.8, emphasis ours). Respondents in this study displayed rage and frustration but also offered glimpses of the imagination required for an altered future. 


\section{Conclusion}

The web of supports for families and mothers are gossamer-thin, providing the barest scaffold for maternal labour. By contrast, the expectations placed on mothers are suffocating, drowning out agency and instinct. It is unsurprising that these tensions are exacerbated in the present moment, even in a relatively privileged sample, such as that found in this study. While we can't guess at how a wider range of mothers might have responded to this study, communities hardest hit by COVID—Black and Indigenous communities, people with disabilities, for example-communities, not coincidentally in which mothering is under greatest scrutiny-will experience heightened impacts of the expectations of motherhood (Friedman and Satterthwaite 2021).

This study suggests that good motherhood requires a state of constant self-abnegation, and that this state has been exacerbated, in many cases, by the present context of COVID. Mothers who prioritized their needs reported a great deal of ambivalence and uneasiness and often they qualified their attempts as necessary for them to ensure they could care for children appropriately (for example, doing a workout to reset in order to be sufficiently patient with children). In light of this need for total abasement, it is not surprising that pre-existing tensions around working motherhood are amplified in the current pandemic in which workplaces require total commitment and reliability at the same time that parenting is meant to be constant and all consuming. O'Reilly and Green argue,

It is more specifically mothers who are most impacted by the pandemic because it is mothers who are doing the necessary and arduous carework to sustain our families and communities. However, few are recognizing, let alone supporting, mothers as frontline workers or acknowledging and appreciating what mothers are managing and accomplishing in their homes under unimaginable circumstances. (O'Reilly and Green 2021, 18)

In other words, mothers are set up to fail in the present capitalist and patriarchal context (Ladd-Taylor 2004; Fraser 2016).

It is imperative to note that many mothers have always worked, that the judgment of working motherhood is classed and raced (Hill Collins 1993) and indeed, is almost irrelevant in the present day in which reliance on two adult incomes in many households is barely adequate to meet burdens and expectations of contemporary life. Nonetheless, it was notable that the cognitive burden of worrying about children and of feeling inadequate for failing to be constantly available for children's needs was deeply gendered and was discussed across all diversities and intersections within this study. This echoes findings from Johnston, Mohammed and van der Linden: "Despite continued gendered disparities in average employment earnings, the persistent asymmetric allocation of caring work between women and men is not solely a reflection of relative differences in income. Rather, it belies social constructions of gender roles that position the primary role of women as caregivers and nurturers" $(2020,1133)$.

The extent to which the current paradigm around families rests on neoliberal expectations of self-reliance and outdated racist, classist, and homophobic expectations around male breadwinner/female caregiver models has been exposed by the present moment. As educational spaces have opened up as public health guidelines changed, the "choice" to keep children home unambiguously heightens poverty for families with the thinnest margin of economic security (O'Reilly 2020); for some families this may increase involvement with child welfare agencies under the guise of "protection." The mothers in this study, while skewing toward privileged social locations, are still experiencing the calcifying of gender expectations, the annihilation of agency, and the erasure of endless hours of unpaid labour. We note the following: "Motherwork intensified for mothers when support systems and relational connections dwindled or stopped completely due to the restrictions imposed by pandemic protocols. Not only did intensive mothering become more intense, but it also became unsupported and more isolating" (O’Reilly and Green 2021, 26).

Sara Peterson notes in the title of her 2020 article, "After the pandemic, we'll finally have to address the impossible state of motherhood." This "impossible state" is characterized by the burdens of neoliberalism, sexism, and other oppressions and is exacerbated by overwhelming self-blame and the burden of expectation of how good mothers should behave. We argue that the material conditions of motherhood must be altered but that such a shift must be accompanied by a concomitant shift in thinking, one that understands motherhood as overwhelming and dynamic. Such an approach would, at the very least, allow mothers to forgive themselves for failing to meet an impossible and oppressive set of standards. 


\section{Endnotes}

1. In keeping with the Mad Studies movement, we use the term "madness" here as "a term reclaimed by those who have been pathologized/psychiatrized as "mentally ill,' and as a way of taking back language that has been used to oppress.... We are referring to a movement, an identity, a stance, an act of resistance, a theoretical approach, and a burgeoning field of study" (Poole and Ward 2013, 96).

2. All quotations in section headings are drawn from survey responses.

\section{Works Cited}

boyd, danah. 2016. July 11. "Blame Society, Not the Screen Time.” New York Times, July 11, 2016.

Braun, Virginia and Victoria Clarke. 2006. "Using Thematic Analysis in Psychology." Qualitative Research in Psychology 3(2): 77-101.

Caplan, Paula. 1989. Don't Blame Mother: Mending the Mother-Daughter Relationship. New York: Harper and Row.

Cerniglia, Luca and Silvia Cimino. 2020. "A Reflection on Controversial Literature on Screen Time and Educational Apps Use in 0-5 Years Old Children." International Journal of Environmental Research and Public Health 17(13): 4641, 1-4.

Cohen, Patricia and Tiffany Hsu. 2020. "Pandemic Could Scar a Generation of Working Mothers." New York Times, June 3, 2020. https://www.nytimes.com/ 2020/06/03/business/economy/coronavirus-workingwomen.html

Ennis, Linda. Editor. 2014. Intensive Mothering: The Cultural Contradictions of Modern Motherhood. Toronto: Demeter Press.

Fraser, Nancy. 2016. "Contradictions of Capital and Care.” New Left Review 100 (July-Aug 2016): 99-117.

Fortier, Craig and Edward Hon-Sing Wong. 2018. "The Settler Colonialism of Social Work and the Social Work of Settler Colonialism." Settler Colonial Studies 9(4): 120.

Friedman, May. 2015. "Mother Blame, Fat Shame and Moral Panic: 'Obesity' and Child Welfare.” Fat Studies:
An Interdisciplinary Journal of Body Weight and Society 4(1): 14-27.

Friedman, May and Satterthwaite, Emily. (2021). "Same Storm, Different Boats: Some Thoughts on Gender, Race and Class in the Time of COVID." In Mothers, Mothering and the COVID-19 Pandemic: Dispatches from a Pandemic, edited by Andrea O'Reilly and Fiona Joy Green, 51-62. Toronto: Demeter Press.

Golestaneh Ladan, Joel Neugarten, Molly Fisher, Henny H. Billett, Morayma Reyes Gil, Tanya Johns, Milagros Yunes, Michele H. Mokrzycki, Maria Coco, Keith C. Norris, Hector R. Perez, Shani Scott, Ryung S. Kim and Eran Bellin. 2020. "The Association of Race and COVID-19 Mortality.” EClinical Medicine 25(100455) August 1, 2020.

Hays, Sharon. 1998. The Cultural Contradictions of Motherhood. Yale University Press.

Hill Collins, Patricia. 1993. "Shifting the Center: Race, Class and Feminist Theorizing about Motherhood." In Mothering: Ideology, Experience and Agency edited by Evelyn Nakano Glenn, Grace Chang and Linda Rennie Forcey, 45-65. New York: Routledge.

Johnston, Regan M., Anwar Mohammed and Clifton van der Linden. 2020. "Evidence of Exacerbated Gender Inequality in Child Care Obligations in Canada and Australia During the COVID-19 Pandemic." Politics and Gender 16: 1131-1141.

Kisner, Jordan. 2021. "The Lockdown Showed How the Economy Exploits Women. She Already Knew.” The New York Times Magazine, February 17, 2021. https:// www.nytimes.com/2021/02/17/magazine/waged-housework.html

Ladd-Taylor, Molly. 2004. "Mother-Worship/MotherBlame: Politics and Welfare in an Uncertain Age." The Journal of the Association for Research on Mothering 6(1), 7-15.

Nathanson, Jessica and Laura Camille Tuley, eds. 2009. Mother Knows Best: Talking Back to the 'Experts'. Toronto: Demeter Press.

O’Reilly, Andrea. 2004. "Introduction." In Mother Outlaws: Theories and Practices of Empowered Mothering edited by Andrea O'Reilly, 1-30. Toronto: Canadian Scholars' Press.

O’Reilly, Andrea. 2007. Editor. Maternal theory: Essential Readings. Toronto: Demeter Press, 2007. 
O’Reilly, Andrea. 2019. "Matricentric Feminism: A

Feminism for Mothers." Journal of the Motherhood Initiative 10(1-2), 13-26.

O'Reilly, Andrea. 2020. "'Trying to Function in the Unfunctionable': Mothers and COVID-19." Journal of the Motherhood Initiative 11(1), 7-24.

O’Reilly, Andrea and Fiona Joy Green, eds. 2021. Mothers, Mothering and COVID-19: Dispatches from a Pandemic. Toronto: Demeter Press.

Peterson, Sara. 2020. "After the Pandemic, We'll Finally Have to Address the Impossible State of Motherhood." InStyle Magazine, June 24, 2020. https://ca.style.yahoo.$\mathrm{com} /$ pandemic-ll-finally-address-impossible-

193034205.html

Pon, Gorden, Doret Phillips, Jennifer Clarke, and Idil Abdillahi. 2017. "Who's Protecting Whom? Child Welfare and Policing Black Families." In Doing Anti-Oppressive Practice: Social Justice Social Work, 3rd edition, edited by Donna Baines, 70-88. Halifax: Fernwood Press.

Poole, Jennifer M. and Jennifer Ward. 2013. “Breaking Open the Bone': Storying, Sanism, and Mad Grief. In Mad Matters: A Critical Reader in Canadian Mad Studies, edited by Brenda A. LeFrancois, Robert Menzies, and Geoffrey Reaume, 94-104. Toronto: Canadian Scholars' Press.

Sodha, Sonia. 2020. "Is the Pandemic Sending us Back to the 1950s When it Comes to Taking Care of the Home?" The Guardian, June 21, 2020. https://www.theguardian.com/commentisfree/2020/jun/21/is-the-pandemic-sending-us-back-to-the-1950s-when-it-comes-totaking-care-of-the-home-

Takseva, Tatjana. 2018. "Motherhood Studies and Feminist Theory: Elisions and Intersections." Journal of the Motherhood Initiative 9(1), 177-194.

Vandenbeld Giles, Melinda, ed. 2014. Mothering in the Age of Neoliberalism. Toronto: Demeter Press.

Warner, Judith. 2005. Motherhood in the Age of Anxiety. New York : Riverhead Books.

Wenham, Clare, Julia Smith and Rosemary Morgan. 2020. "COVID-19: The Gendered Impacts of the Outbreak." The Lancet 295 (March 14, 2020).: 846-847. 